\title{
Germinação de Sementes de Sida rhombifolia E Brachiaria decumbens INFLUENCIADA POR VINHAÇA, FLEGMAÇA E ÓLEO DE FÚSEL ${ }^{1}$
}

\author{
Germination of Sida rhombifolia and Brachiaria decumbens Seeds Influenced by Vinasse, \\ Flegmass and Fusel Oil
}

AZANIA, A.A.P.M. ${ }^{2}$, MARQUES, M.O. ${ }^{3}$, PAVANI, M.C.M.D. ${ }^{4}$ e AZANIA, C.A.M. ${ }^{5}$

\begin{abstract}
RESUMO - Este trabalho objetivou avaliar, em condições de laboratório, a germinação de sementes de Sida rhombifolia e Brachiaria decumbens submetidas à aplicação de vinhaça, flegmaça e óleo de fúsel. Esses subprodutos, nas concentrações de 12,5; 25,0; 50,0; e 100,0\% (v/v), e as testemunhas (água com pH e osmolalidade corrigidos, em função da caracterização realizada nos subprodutos e em suas diluições) foram aplicados diretamente em 100 sementes acondicionadas em caixas de plástico, utilizando papel como substrato. O delineamento experimental foi o inteiramente casualizado, e as médias obtidas foram submetidas ao teste de Tukey. As sementes de Sida rhombifolia submetidas ao óleo de fúsel não germinaram e apresentaram redução na viabilidade, principalmente nas maiores concentrações de aplicação. As sementes de Brachiaria decumbens submetidas à maior concentração de flegmaça apresentaram tendência de redução da viabilidade e do índice de velocidade de germinação (IVG). Na presença do óleo de fúsel as sementes de Brachiaria decumbens não germinaram e apresentaram-se totalmente inviáveis.
\end{abstract}

Palavras-chave: subprodutos, plantas daninhas.

\begin{abstract}
This research aimed to evaluate the effects of vinasse, flegmass and fusel oil (distillery by-products) on the germination of Sida rhombifolia and Brachiaria decumbens seeds, under laboratory conditions. By-product concentrations $(12.5 ; 25.0 ; 50.0$ and $100.0 \% \mathrm{v} / \mathrm{v}$ ) and the controls (water with $\mathrm{pH}$ and osmolality amended according to by-product composition and levels) were applied directly on plastic boxes filled with 100 seeds of the same species. The experiment was arranged in a randomized complete design and the data were submitted to the Tukey test. Sida rhombifolia seeds submitted to fusel oil did not germinate, reducing seed viability mainly at the largest application rates. Brachiaria decumbens seeds submitted to the highest flegmass rate tended to reduce seed viability and germination speed index (GSI). Brachiaria decumbens seeds submitted to fusel oil did not germinate and were rendered totally unviable.
\end{abstract}

Key words: by-products, weeds.

\section{INTRODUÇÃO}

A produção de açúcar e álcool a partir de cana-de-açúcar gera uma série de subprodutos que permitem um aproveitamento total da matéria-prima, tornando a indústria brasileira do açúcar e do álcool um exemplo no que se refere ao reaproveitamento dos resíduos gerados.

1 Recebido para publicação em 13.5.2003 e na forma revisada em 12.12.2003.

Parte da dissertação de Mestrado em Produção Vegetal apresentada à FCAV/UNESP, Jaboticabal-.SP.

2 Mestranda em Produção Vegetal, Bolsista CNPq; ${ }^{3}$ Prof. Dr. do Dep. de Tecnologia da FCAV/UNESP; ${ }^{4}$ Prof ${ }^{a}$ Dr ${ }^{a}$ do Dep. de Biologia Aplicada à Agropecuária da FCAV/UNESP; ${ }^{5}$ Doutorando em Produção Vegetal da FCAV/UNESP, Via de acesso Prof. Paulo Donato Castellane, s/n ${ }^{\circ}, 14.884-900$ Jaboticabal-SP. 
O principal efluente das destilarias de álcool é a vinhaça, sendo produzida, em média, na proporção de 13:1 L de vinhaça e álcool, respectivamente. Considerando os nutrientes (principalmente o potássio) e a matéria orgânica que apresenta, de acordo com Glória \& Orlando Filho (1984), sua utilização nas lavouras de cana-de-açúcar tem aumentado, em substituição parcial ou total à adubação mineral de parte dos canaviais.

A flegmaça, resíduo da retificação do flegma nas destilarias, segundo Zarpelon (1982), é uma água com traços de óleo de fúsel, sendo produzidos, em média, 2,8 L para cada litro de álcool. Quando unida à vinhaça, pode ser usada na fertirrigação.

O óleo de fúsel é a fração menos volátil obtida durante a produção do álcool etílico. A produção média deste subproduto é estimada em 2,5 L para cada 1.000 L de álcool. No entanto, considerando que anualmente no Brasil são produzidos aproximadamente 15 bilhões de litros de etanol, tem-se uma quantidade de 37,5 milhões de litros de óleo de fúsel no mercado (Pérez et al., 2001). Entretanto, apesar de o óleo de fúsel constituir um dos principais subprodutos da redestilação do álcool, ainda não é devidamente aproveitado pelas usinas.

A maioria dos trabalhos encontrados com subprodutos da indústria sucroalcooleira aborda aspectos da influência do uso deles na fertilidade do solo e nutrição de culturas, com raras menções às plantas infestantes. Balbo Jr. (1984) estudou os efeitos da vinhaça sobre a emergência e o desenvolvimento inicial do fedegoso (Cassia tora) cultivado em vasos e concluiu que por esta afetou negativamente a velocidade de emergência da planta. Buss et al. (1978) testaram o efeito da aplicação de vinhaça em mistura com herbicidas sobre a população de plantas daninhas na cultura da cana-deaçúcar e constataram que os herbicidas não tiveram sua eficácia prejudicada quando aplicados com vinhaça.

No entanto, torna-se interessante averiguar os efeitos dos demais subprodutos da indústria sucroalcooleira sobre diferentes plantas daninhas. Nesse sentido, Arevalo \& Bertoncini (1999) comentaram que Brachiaria decumbens está entre as piores plantas daninhas que infestam áreas com resíduos de colheita de cana-de-açúcar e Sida rhombifolia é uma das espécies que mais infestam o Estado de São Paulo (Cardoso, 1990).

Na literatura, verifica-se que nem todos os subprodutos de agroindústrias têm potencial para aumentar a fertilidade dos solos, mas nem por isso deixam de ter utilidade. Considerandose as poucas informações sobre utilização de subprodutos/resíduos em plantas daninhas, esta pesquisa objetivou avaliar em condições de laboratório a germinação e viabilidade das sementes de Sida rhombifolia e Brachiaria decumbens submetidas à aplicação de vinhaça, flegmaça e óleo de fúsel.

\section{MATERIAL E MÉTODOS}

O experimento foi instalado e conduzido no Laboratório de Biologia e Manejo de Plantas Daninhas, da Faculdade de Ciências Agrárias e Veterinárias de Jaboticabal -SP.

Sementes de Sida rhombifolia (guanxuma) e Brachiaria decumbens (capim-braquiária) foram adquiridas na Shokucho do Brasil Agrícola Ltda. Por ocasião do experimento, as sementes foram selecionadas visualmente por tamanho e aspecto e a seguir contadas, eliminando-se aquelas defeituosas ou carunchadas.

Caixas de plástico do tipo gerbox foram utilizadas para acondicionar uma folha de papel germibox; sobre este foram postas sementes de guanxuma ou capim-braquiária, em número de 100, montando cinco repetições para cada tratamento. Sobre as sementes foram aplicados $10 \mathrm{~mL}$ de cada um dos subprodutos separadamente (vinhaça, flegmaça e óleo de fúsel), misturados com água, nas concentrações de 12,5; 25,0; 50,0; e 100,0\%, após prévia agitação. A vinhaça foi analisada quanto à composição química (Tabela 1), e o óleo de fúsel e a flegmaça foram analisados por cromatografia gasosa (Tabela 2).

Em virtude da caracterização prévia dos subprodutos, em suas diferentes concentrações, quanto a osmolalidade e pH (Tabela 3), verificou-se a necessidade de elaborar testemunhas adicionais para cada um deles.

Para as testemunhas envolvendo $\mathrm{pH}$, foram preparadas soluções tomando-se como referência os valores de leituras da Tabela 3 . O preparo das soluções consistiu da utilização 
de água sob constante agitação, acrescida de hidróxido de sódio $0,01 \mathrm{~N}$ ou ácido clorídrico $0,01 \mathrm{~N}$ até a obtenção da leitura de $\mathrm{pH}$ desejada. Entretanto, considerando os valores de $\mathrm{pH}$ para cada subproduto em todas as concentrações, optou-se por elaborar soluções com pH 4,5; 5,5; e 6,0 para vinhaça, flegmaça e óleo de fúsel, respectivamente.

Para as testemunhas de osmolalidade, foram preparadas soluções com água e polietilenoglicol 6000 (PEG). Segundo Villela et al. (1991), o polietilenoglicol $\left(\mathrm{HOCH}_{2}\right.$ $\left.\left(\mathrm{CH}_{2} \mathrm{OCH}_{2}\right)_{\mathrm{n}} \mathrm{CH}_{2} \mathrm{OH}\right)$ é o soluto mais utilizado para o condicionamento osmótico, por ser quimicamente inerte e não-tóxico às sementes. No preparo destas soluções, foi dissolvido PEG $6000 \mathrm{em} 1 \mathrm{~kg}$ de água destilada $\left(25^{\circ} \mathrm{C}\right)$ e, após a total homogeneização, obtidas as leituras em osmômetro (Wescor 5500), considerando os valores de osmolalidade para cada um dos subprodutos em todas as concentrações (Tabela 3). Assim, as leituras de osmolalidade foram ajustadas em 77, 157 e $201 \mathrm{mmol} \mathrm{kg}^{-1}$ para vinhaça, $57 \mathrm{mmol} \mathrm{kg} \mathrm{kg}^{-1}$ para flegmaça e

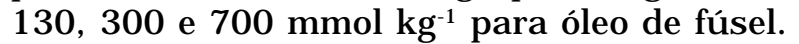
Para finalizar as soluções, todas foram caracterizadas também quanto ao $\mathrm{pH}$, utilizando-se o mesmo procedimento de preparo e valores das testemunhas que envolveram $\mathrm{pH}$.

As caixas gerbox contendo as sementes de guanxuma e capim-braquiária foram acondicionadas em câmara de germinação regulada para $35 / 20{ }^{\circ} \mathrm{C}$ e fotoperíodo de $14 / 10 \mathrm{~h}$ de luz/ escuro, de acordo com Smith et al. (1992) e Brasil (1992), durante 21 dias, com contagens diárias de germinação. Nos tratamentos que envolveram a vinhaça, o tempo de contato com as sementes foi de 48 horas, a fim de evitar a rápida proliferação de fungos nas caixas gerbox, devido ao alto conteúdo de nutrientes presentes na vinhaça.
O experimento foi conduzido em delineamento inteiramente casualizado, sendo oito tratamentos para vinhaça e óleo de fúsel e seis para flegmaça, todos em cinco repetições, com 100 sementes de cada uma das espécies estudadas. As variáveis analisadas foram: porcentagem de germinação; viabilidade (pelo teste de tetrazólio, conforme Brasil, 1992); índice de velocidade de germinação (IVG), de acordo com Maguire (1962); e tempo médio de germinação, conforme Labouriau (1983).

A análise de variância pelo teste $F$ foi utilizada para avaliar o efeito dos tratamentos sobre as variáveis analisadas; posteriormente, para comparação das médias dos tratamentos, foi utilizado o teste de Tukey em nível de 5\% de probabilidade.

\section{RESULTADOS E DISCUSSÃO}

Analisando os resultados da análise química da vinhaça (Tabela 1), verifica-se que, dentre os macronutrientes, destaca-se o potássio em maior quantidade. Além disso, a presença de matéria orgânica e de micronutrientes confere potencial a esse subproduto de promover melhorias à fertilidade do solo, em razão das proporções desbalanceadas dos nutrientes diante das exigências nutricionais das plantas. Outro problema é a variabilidade na composição que, com freqüência, esse subproduto apresenta. De acordo com Korndorfer \& Anderson (1997), a composição da vinhaça depende de fatores como a origem e a composição da matéria-prima e o tipo de equipamento para operação de destilação; com isso, a análise química pode variar de uma usina para outra, ou mesmo dentro de uma mesma usina, segundo a matéria-prima empregada.

A análise da flegmaça por cromatografia gasosa (Tabela 2) indica haver basicamente

Tabela 1 - Resultados da análise química de amostra de vinhaça proveniente da Usina São Martinho. Guariba-SP, 2003'

\begin{tabular}{|c|c|c|c|c|c|c|c|c|c|c|c|c|}
\hline \multicolumn{10}{|c|}{ Análise Química } \\
\hline \multirow{2}{*}{$\mathrm{pH}$} & $\mathrm{M} . \mathrm{O}$ & $\mathrm{N}$ & $\mathrm{P}$ & $\mathrm{K}$ & $\mathrm{Ca}$ & $\mathrm{Mg}$ & $\mathrm{S}$ & $\mathrm{Cu}$ & $\mathrm{Fe}$ & $\mathrm{Mn}$ & $\mathrm{Zn}$ \\
\cline { 2 - 11 } & $(\%)$ & \multicolumn{10}{|c|}{$\left(\mathrm{kg} \mathrm{m}^{-3}\right)$} & \multicolumn{5}{|c|}{} \\
\hline 4,2 & 1,57 & 0,38 & 0,045 & 2,17 & 0,60 & 0,50 & 1,87 & 1,0 & 51 & 3,9 & 2,0 \\
\hline
\end{tabular}

1/ Análise realizada no Laboratório de Análise Química de Solo e Planta do Departamento de Recursos Naturais e Proteção Ambiental Centro de Ciências Agrárias, UFSCar. Araras-SP. 
etanol em sua composição $(0,043 \% \mathrm{v} / \mathrm{v})$, o que é discordante de Zarpelon (1982), segundo o qual a flegmaça é basicamente uma água com traços de óleo de fúsel. Na composição do óleo de fúsel são observados vários constituintes, sendo o álcool isoamílico, de grande valor comercial, presente em maior quantidade, seguido por etanol e isobutanol (Tabela 2).

Nos tratamentos com diferentes concentrações de vinhaça, o tempo de contato com as sementes foi de 48 horas e não de 21 dias, como ocorreu com os demais subprodutos, devido ao alto conteúdo de nutrientes presentes, o que desencadeou uma rápida proliferação de fungos nas caixas gerbox. O tempo de 48 horas não foi suficiente para que todas as sementes iniciassem o processo de germinação; por isso, como se vê na Tabela 4 , somente as testemunhas das duas espécies testadas conseguiram iniciar a germinação.

Os valores de osmolalidade da vinhaça, caracterizados para as testemunhas, não exerceram efeito sobre a germinação das sementes para as duas espécies estudadas, embora tenha sido observada uma discreta tendência de redução com o aumento da osmolalidade. Essa tendência, para a guanxuma, apresenta-se

Tabela 2 - Composição química do óleo de fúsel e da flegmaça por cromatografia gasosa, provenientes da Usina São Carlos. Jaboticabal-SP, 2003- ${ }^{1}$

\begin{tabular}{|c|c|c|}
\hline Componente & Óleo de fúsel (\%) & Flegmaça (\%) \\
\hline Etanol & 11,70 & 0,043 \\
\hline n-propanol & 0,83 & - \\
\hline i-butanol & 8,47 & - \\
\hline n-butanol & 0,21 & - \\
\hline i-amílico & 28,66 & - \\
\hline n-amílico & 0,12 & - \\
\hline
\end{tabular}

1/ Análise realizada no Departamento de Agroindústria, Alimentos e Nutrição, Setor de Açúcar e Álcool da ESALQ/USP. Piracicaba-SP. menos pronunciada, o que pode ser atribuído ao possível processo de dormência em que as sementes ainda se encontravam. De acordo com Cardoso (1990, 1991), a germinação de guanxuma (Sida rhombifolia) é inibida pelo tegumento, por causa da restrição à entrada de água no interior da semente.

Considerando os resultados de viabilidade das sementes, observa-se a mesma tendência mencionada anteriormente apenas para as sementes de guanxuma. Christoffoleti \& Bacchi (1985) também verificaram que diferentes doses de vinhaça influenciam a população de guanxuma, pois, à medida que diminuíram a dose, constataram o aumento da sua população.

Constatou-se que a germinação da guanxuma foi indiferente às concentrações de flegmaça testadas, reforçando a possibilidade da manifestação de dormência pelas sementes dessa espécie. O mesmo comportamento foi verificado para os valores de viabilidade de sementes. As sementes de capim-braquiária apresentaram porcentagem de germinação média de $51,43 \%$ (valores observados). O aumento das concentrações de flegmaça resultou em tendência de redução da porcentagem de germinação e viabilidade das sementes. Como se pode constatar na Tabela 2, na composição da flegmaça encontra-se apenas etanol, permitindo a inferência de que seria este o responsável pelos resultados que demonstraram redução da viabilidade das sementes quando a concentração de 100,0\% foi empregada.

Os valores de índice de velocidade de germinação, que possibilitam avaliar as diferenças de vigor entre as sementes (Nakagawa, 1994), e o tempo médio de germinação (Tabela 5), avaliados nas sementes de guanxuma, não foram influenciados pela flegmaça e por suas concentrações.

Tabela 3 - Caracterização prévia de osmolalidade e pH das amostras de vinhaça, flegmaça e óleo de fúsel. Jaboticabal, 2003

\begin{tabular}{|l|c|c|c|c|c|c|c|c|}
\hline \multirow{3}{*}{ Subproduto } & \multicolumn{4}{|c|}{ Osmolalidade $\mathrm{I}^{\prime /}\left(\mathrm{mmol} \mathrm{kg}^{-1}\right)$} & \multicolumn{4}{c|}{$\mathrm{pH}^{\underline{2}^{\prime}}$} \\
\cline { 2 - 9 } & \multicolumn{4}{|c|}{$(\%)$} & \multicolumn{1}{c|}{$(\%)$} \\
\cline { 2 - 9 } & 12,5 & 25,0 & 50,0 & 100,0 & 12,5 & 25,0 & 50,0 & 100,0 \\
\hline Vinhaça & 71 & 83 & 157 & 210 & 4,75 & 4,68 & 4,63 & 4,57 \\
Flegmaça & 54 & 55 & 52 & 57 & 5,96 & 4,97 & 4,58 & 4,28 \\
Óleo de fúsel & 141 & 166 & 174 & 706 & 6,61 & 6,39 & 6,11 & 5,60 \\
\hline
\end{tabular}

${ }^{1 /}$ Determinada por osmômetro Wescor 5500. ${ }^{2 /}$ Determinação realizada por aparelho medidor de $\mathrm{pH}$. 
Tabela 4 - Percentual de germinação e viabilidade das sementes de Sida rhombifolia (SIDRH) e Brachiaria decumbens (BRADC) submetidas, por 48 horas, ao contato com vinhaça e, por 21 dias, com flegmaça e óleo de fúsel, em diferentes concentrações. Média de cinco repetições. Jaboticabal, 2003

\begin{tabular}{|c|c|c|c|c|c|c|c|c|c|c|}
\hline \multirow{3}{*}{$\begin{array}{l}\text { Trata- } \\
\text { mento }\end{array}$} & \multirow{3}{*}{\multicolumn{2}{|c|}{ Concentração }} & \multicolumn{4}{|c|}{ Germinação } & \multicolumn{4}{|c|}{ Viabilidade } \\
\hline & & & \multicolumn{2}{|c|}{ SIDRH } & \multicolumn{2}{|c|}{ BRADC } & \multicolumn{2}{|c|}{ SIDRH } & \multicolumn{2}{|c|}{ BRADC } \\
\hline & & & $\begin{array}{l}\text { Valor } \\
\text { transf. }^{1 /}\end{array}$ & $\begin{array}{l}\text { Valor } \\
\text { obs. }^{2 \prime}\end{array}$ & $\begin{array}{l}\text { Valor } \\
\text { transf. }^{1 /}\end{array}$ & $\begin{array}{l}\text { Valor } \\
\text { obs. }{ }^{2 /}\end{array}$ & Valor transf. $^{1 /}$ & $\begin{array}{l}\text { Valor } \\
\text { obs. }{ }^{2 / 1}\end{array}$ & $\begin{array}{l}\text { Valor } \\
\text { transf. }^{1 /}\end{array}$ & $\begin{array}{l}\text { Valor } \\
\text { obs. }{ }^{2 /}\end{array}$ \\
\hline \multirow{12}{*}{ 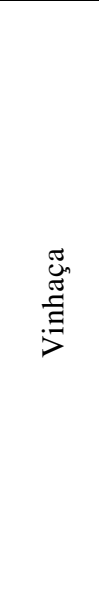 } & \multirow{4}{*}{$(\mathrm{v} / \mathrm{v})$} & 12,5 & $4,05 \mathrm{~b}$ & 0,0 & $4,05 \mathrm{~b}$ & 0,0 & $79,84 \mathrm{a}$ & 95,6 & $70,42 \mathrm{a}$ & 87,8 \\
\hline & & 25,0 & $4,05 \mathrm{~b}$ & 0,0 & $4,05 \mathrm{~b}$ & 0,0 & $74,18 \mathrm{a}$ & 90,8 & $68,35 \mathrm{a}$ & 85,4 \\
\hline & & 50,0 & $4,05 \mathrm{~b}$ & 0,0 & $4,05 \mathrm{~b}$ & 0,0 & $77,06 \mathrm{a}$ & 94,2 & $65,16 a$ & 81,6 \\
\hline & & 100,0 & $4,05 \mathrm{~b}$ & 0,0 & $4,05 \mathrm{~b}$ & 0,0 & $72,25 \mathrm{a}$ & 89,8 & $73,60 \mathrm{a}$ & 90,8 \\
\hline & $\mathrm{pH}$ & 4,5 & $15,48 \mathrm{a}$ & 7,4 & $28,83 \mathrm{a}$ & 22,8 & $73,69 \mathrm{a}$ & 91,0 & $67,80 \mathrm{a}$ & 84,6 \\
\hline & \multirow{3}{*}{$\begin{array}{l}\text { PEG } \\
\left(\mathrm{mmol} \mathrm{kg}^{-1}\right)\end{array}$} & 77 & $12,30 \mathrm{a}$ & 4,4 & $30,70 \mathrm{a}$ & 26,0 & $70,20 \mathrm{a}$ & 87,8 & $70,12 \mathrm{a}$ & 87,6 \\
\hline & & 157 & $11,85 \mathrm{a}$ & 4,0 & $29,64 \mathrm{a}$ & 24,0 & 74,69 a & 92,0 & 73,77 a & 91,2 \\
\hline & & 201 & $12,94 \mathrm{a}$ & 5,2 & $26,60 \mathrm{a}$ & 19,8 & $70,40 \mathrm{a}$ & 88,2 & $68,81 \mathrm{a}$ & 84,4 \\
\hline & \multicolumn{2}{|l|}{ Média } & 8,60 & & 16,50 & & 74,04 & & 69,63 & \\
\hline & \multicolumn{2}{|l|}{ d.m.s. } & 7,16 & & 5,55 & & 10,30 & & 11,05 & \\
\hline & \multicolumn{2}{|l|}{$\mathrm{F}$} & $10,12 * *$ & & $121,37 * *$ & & $2,11 \mathrm{NS}$ & & $1,52 \mathrm{NS}$ & \\
\hline & \multicolumn{2}{|l|}{$\mathrm{CV}(\%)$} & 40,64 & & 16,43 & & 6,79 & & 7,75 & \\
\hline \multirow{10}{*}{ 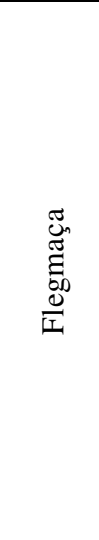 } & \multirow{4}{*}{$(\mathrm{v} / \mathrm{v})$} & 12,5 & $30,50 \mathrm{a}$ & 25,6 & $47,24 \mathrm{a}$ & 53,4 & $50,14 \mathrm{a}$ & 58,4 & $61,65 a b c$ & 77,0 \\
\hline & & 25,0 & $24,64 \mathrm{a}$ & 17,0 & $47,61 \mathrm{a}$ & 54,0 & $47,47 \mathrm{a}$ & 53,8 & $62,12 \mathrm{ab}$ & 86,6 \\
\hline & & 50,0 & $28,74 \mathrm{a}$ & 23,0 & $46,35 \mathrm{a}$ & 51,8 & $48,39 \mathrm{a}$ & 55,4 & $62,75 \mathrm{ab}$ & 77,8 \\
\hline & & 100,0 & $30,44 \mathrm{a}$ & 25,4 & $40,43 \mathrm{a}$ & 41,6 & $50,61 \mathrm{a}$ & 59,2 & $53,49 \mathrm{c}$ & 64,0 \\
\hline & $\mathrm{pH}$ & 5,5 & $20,47 \mathrm{a}$ & 12,8 & $46,91 \mathrm{a}$ & 52,8 & $47,26 \mathrm{a}$ & 53,4 & $59,03 \mathrm{bc}$ & 72,8 \\
\hline & $\begin{array}{l}\text { PEG } \\
\left(\mathrm{mmol} \mathrm{kg}^{-1}\right)\end{array}$ & 57 & $25,89 \mathrm{a}$ & 19,6 & $48,16 \mathrm{a}$ & 55,0 & 51,42 a & 60,6 & $60,47 \mathrm{bc}$ & 75,2 \\
\hline & \multicolumn{2}{|l|}{ Média } & $26,78 \mathrm{a}$ & & 46,12 & & 49,22 & & 61,10 & \\
\hline & \multicolumn{2}{|l|}{ d.m.s. } & 11,98 & & 8,23 & & 5,00 & & 8,48 & \\
\hline & \multicolumn{2}{|l|}{$\mathrm{F}$} & $2,03 \mathrm{NS}$ & & $2,30 \mathrm{NS}$ & & $2,32 \mathrm{NS}$ & & $6,92 * *$ & \\
\hline & \multicolumn{2}{|l|}{$\mathrm{CV}(\%)$} & 22,89 & & 9,13 & & 5,20 & & 7,10 & \\
\hline \multirow{12}{*}{ 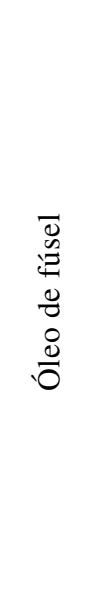 } & \multirow{4}{*}{$(\mathrm{v} / \mathrm{v})$} & 12,5 & $4,05 \mathrm{~b}$ & 0,0 & $4,05 \mathrm{~b}$ & 0,0 & $45,64 \mathrm{bcd}$ & 50,6 & $4,05 \mathrm{~b}$ & 0,0 \\
\hline & & 25,0 & $4,05 \mathrm{~b}$ & 0,0 & $4,05 \mathrm{~b}$ & 0,0 & $40,90 \mathrm{~cd}$ & 42,4 & $4,05 \mathrm{~b}$ & 0,0 \\
\hline & & 50,0 & $4,05 \mathrm{~b}$ & 0,0 & $4,05 \mathrm{~b}$ & 0,0 & $41,72 \mathrm{~cd}$ & 43,8 & $4,05 \mathrm{~b}$ & 0,0 \\
\hline & & 100,0 & $4,05 \mathrm{~b}$ & 0,0 & $4,05 \mathrm{~b}$ & 0,0 & $35,18 \mathrm{~d}$ & 33,0 & $4,05 \mathrm{~b}$ & 0,0 \\
\hline & $\mathrm{pH}$ & 6,0 & 26,96 a & 20,2 & $45,52 \mathrm{a}$ & 50,4 & $64,72 \mathrm{a}$ & 80,0 & 58,78 a & 72,6 \\
\hline & \multirow{3}{*}{$\begin{array}{l}\text { PEG } \\
\left(\mathrm{mmol} \mathrm{kg}^{-1}\right)\end{array}$} & 130 & $24,89 \mathrm{a}$ & 17,4 & $47,74 \mathrm{a}$ & 54,2 & $57,68 \mathrm{ab}$ & 67,8 & $57,70 \mathrm{a}$ & 70,6 \\
\hline & & 300 & $23,33 \mathrm{a}$ & 15,4 & $48,30 \mathrm{a}$ & 55,2 & $54,19 \mathrm{abc}$ & 65,0 & $62,76 \mathrm{a}$ & 78,2 \\
\hline & & 700 & $24,19 \mathrm{a}$ & 16,4 & $46,90 \mathrm{a}$ & 52,8 & $54,69 \mathrm{abc}$ & 66,0 & $60,08 \mathrm{a}$ & 74,4 \\
\hline & \multicolumn{2}{|l|}{ Média } & 14,45 & & 25,58 & & 49,34 & & 31,94 & \\
\hline & d.m.s. & & 4,68 & & 5,58 & & 15,69 & & 6,34 & \\
\hline & $\mathrm{F}$ & & $119,20 * *$ & & $357,26 * *$ & & $8,55^{*} *$ & & $464,97 * *$ & \\
\hline & $\mathrm{CV}(\%)$ & & 15,82 & & 10,65 & & 15,52 & & 9,69 & \\
\hline
\end{tabular}

1/ Valores percentuais transformados em Arc sen (raiz $((x+0,5) / 100))$. 2/ Valores percentuais observados (originais). PEG polietilenoglicol. (v/v) - volume/volume. Médias seguidas de letras iguais nas colunas não diferem entre si pelo teste de Tukey. ** significativo a $1 \%$ de probabilidade pelo teste F. NS - não-significativo. d.m.s. - diferença mínima significativa. 
Tabela 5 - Índice de velocidade de germinação (IVG) e tempo médio de germinação das sementes de Sida rhombifolia (SIDRH) e Brachiaria decumbens (BRADC) submetidas ao contato com flegmaça e óleo de fúsel em diferentes concentrações, por 21 dias. Média de cinco repetições. Jaboticabal, 2003

\begin{tabular}{|c|c|c|c|c|c|c|}
\hline \multirow{2}{*}{ Tratamento } & \multirow{2}{*}{\multicolumn{2}{|c|}{ Concentração }} & \multicolumn{2}{|c|}{ IVG } & \multicolumn{2}{|c|}{ Tempo médio germinação (dias) } \\
\hline & & & SIDRH & BRADC & SIDRH & BRADC \\
\hline \multirow{10}{*}{ Flegmaça } & \multirow{4}{*}{$(\mathrm{v} / \mathrm{v})$} & 12,5 & $9,12 \mathrm{a}$ & $27,31 \mathrm{a}$ & $3,84 \mathrm{a}$ & $2,83 \mathrm{a}$ \\
\hline & & 25,0 & $4,48 \mathrm{a}$ & $25,31 \mathrm{a}$ & $5,59 \mathrm{a}$ & $2,93 \mathrm{a}$ \\
\hline & & 50,0 & 9,19 a & $27,56 \mathrm{a}$ & $3,22 \mathrm{a}$ & $2,71 \mathrm{a}$ \\
\hline & & 100,0 & $7,95 \mathrm{a}$ & $20,41 \mathrm{~b}$ & $4,79 \mathrm{a}$ & $2,84 \mathrm{a}$ \\
\hline & $\mathrm{pH}$ & 5,5 & $4,99 \mathrm{a}$ & $24,98 \mathrm{ab}$ & $4,97 \mathrm{a}$ & $3,01 \mathrm{a}$ \\
\hline & PEG $\left(\mathrm{mmol} \mathrm{kg}^{-1}\right)$ & 57,0 & $7,99 \mathrm{a}$ & $27,63 \mathrm{a}$ & $4,81 \mathrm{a}$ & $2,76 \mathrm{a}$ \\
\hline & \multicolumn{2}{|l|}{ Média } & 7,29 & 25,53 & 4,54 & 2,85 \\
\hline & \multicolumn{2}{|l|}{ d.m.s. } & 9,96 & 6,34 & 2,79 & 0,66 \\
\hline & \multicolumn{2}{|l|}{$\mathrm{F}$} & $0,81 \mathrm{NS}$ & $3,63^{*}$ & $1,90 \mathrm{NS}$ & $0,55 \mathrm{NS}$ \\
\hline & \multicolumn{2}{|l|}{$\mathrm{CV}(\%)$} & 69,96 & 12,71 & 27,34 & 11,87 \\
\hline \multirow{12}{*}{ Óleo de fúsel } & \multirow{4}{*}{$(\mathrm{v} / \mathrm{v})$} & 12,5 & $0,00 \mathrm{~b}$ & $0,00 \mathrm{~b}$ & $0,00 \mathrm{~b}$ & $0,00 \mathrm{~b}$ \\
\hline & & 25,0 & $0,00 \mathrm{~b}$ & $0,00 \mathrm{~b}$ & $0,00 \mathrm{~b}$ & $0,00 \mathrm{~b}$ \\
\hline & & 50,0 & $0,00 \mathrm{~b}$ & $0,00 \mathrm{~b}$ & $0,00 \mathrm{~b}$ & $0,00 \mathrm{~b}$ \\
\hline & & 100,0 & $0,00 \mathrm{~b}$ & $0,00 \mathrm{~b}$ & $0,00 \mathrm{~b}$ & $0,00 \mathrm{~b}$ \\
\hline & $\mathrm{pH}$ & 6,0 & $5,23 a$ & $21,65 a$ & $5,20 a$ & $3,26 \mathrm{a}$ \\
\hline & \multirow{3}{*}{ PEG $\left(\mathrm{mmol} \mathrm{kg}{ }^{-1}\right)$} & 130,0 & $4,07 \mathrm{a}$ & $20,50 \mathrm{a}$ & $6,77 \mathrm{a}$ & $3,41 \mathrm{a}$ \\
\hline & & 300,0 & $3,95 a$ & $23,92 \mathrm{a}$ & $6,38 \mathrm{a}$ & $3,10 \mathrm{a}$ \\
\hline & & 700,0 & $4,59 \mathrm{a}$ & $22,42 \mathrm{a}$ & $6,07 \mathrm{a}$ & $3,22 \mathrm{a}$ \\
\hline & \multicolumn{2}{|l|}{ Média } & 2,22 & 11,06 & 3,05 & 1,62 \\
\hline & \multicolumn{2}{|l|}{ d.m.s. } & 2,13 & $\begin{array}{l}6,02 \\
6,02\end{array}$ & 1,80 & 0,48 \\
\hline & \multicolumn{2}{|l|}{$\mathrm{F}$} & $27,05 * *$ & $81,46 * *$ & $70,04 * *$ & $271,65 * *$ \\
\hline & \multicolumn{2}{|l|}{$\mathrm{CV}(\%)$} & 46,55 & 26,57 & 28,82 & 14,52 \\
\hline
\end{tabular}

PEG - polietilenoglicol. (v/v) - volume/volume. Médias seguidas de letras iguais nas colunas não diferem entre si pelo teste de Tukey. ** significativo a $1 \%$ de probabilidade pelo teste $\mathrm{F}$. * significativo a $5 \%$ de probabilidade pelo teste $\mathrm{F}$. NS - não-significativo. d.m.s. diferença mínima significativa.

Nas sementes de capim-braquiária, a média de IVG foi de 25,53. Quando do contato das sementes com a flegmaça na concentração de $100 \%$ (Tabela 5), verificou-se redução no IVG em relação às demais concentrações e ao tratamento testemunha ajustado ao valor de osmolalidade correspondente a $57 \mathrm{mmol} \mathrm{kg}^{-1}$.

Dentre os subprodutos testados, o óleo de fúsel foi o que mais interferiu na germinação, na viabilidade, no IVG e no tempo médio de germinação das sementes (Tabelas 4 e 5). Este subproduto apresentou teores elevados de álcool isoamílico $(28,66 \% \mathrm{p} / \mathrm{p})$, seguido pelo etanol $(11,70 \%$ p/p) e demais álcoois identificados por cromatografia gasosa, que se encontram na Tabela 2. Pérez et al. (2000), coletando amostras do óleo de fúsel em diversas destilarias, e Vauclair et al. (1997) observaram também que o álcool isoamílico foi um composto majoritário nas amostras.

Nenhuma das espécies testadas germinou nas diferentes concentrações do óleo de fúsel durante o período de 21 dias (Tabela 4). Foi possivel o cálculo de IVG apenas para testemunhas. As sementes de capim-braquiária que receberam aplicação de óleo de fúsel também não germinaram, porém suas testemunhas tiveram valores de aproximadamente $50 \%$ de germinação.

A viabilidade das sementes de guanxuma sofreu redução à medida que se aumentou a concentração do óleo de fúsel, fazendo com que o subproduto puro diferisse de todas as testemunhas, mas não de suas próprias 
concentrações (Tabela 4). O fato de as sementes possivelmente se apresentarem dormentes influenciou a viabilidade, porque, devido à restrição à entrada dos subprodutos no interior delas, aproximadamente $42,45 \%$ (dados observados) daquelas submetidas aos subprodutos permaneceram viáveis ao final do período experimental (21 dias).

As sementes de capim-braquiária mostraram-se sensíveis ao óleo de fúsel, tornando-se inviáveis quando em contato com o subproduto, independentemente da dose empregada. As testemunhas não foram diferentes entre si, apresentando viabilidade em torno de $70 \%$. Deve-se ressaltar que, dentre os produtos testados, o óleo de fúsel foi o que apresentou os maiores valores de osmolalidade (Tabela 4).

Considerando que os subprodutos têm suas composições variando segundo a origem e levando-se em conta as condições em que foram testados esses materiais, pode-se concluir que as sementes de Sida rhombifolia, quando submetidas ao óleo de fúsel, não germinaram e apresentaram redução na viabilidade, principalmente nas maiores concentrações de aplicação. No entanto, as sementes de Brachiaria decumbens submetidas à maior concentração de flegmaça apresentaram tendência de redução no percentual de viabilidade e IVG. $\mathrm{Na}$ presença do óleo de fúsel as sementes de Brachiaria decumbens não germinaram e apresentaram-se totalmente inviáveis.

\section{LITERATURA CITADA}

AREVALO, R. A.; BERTONCINI, E. I. Manejo químico de plantas daninhas nos resíduos de colheita de cana crua.

Stab: Açúcar, Álcool Subprod., v. 17, n. 4, p. 36-38, 1999.

BALBO JR., L. Estudos preliminares dos efeitos da vinhaça sobre a emergência e desenvolvimento inicial de plantas daninhas. I - Fedegoso (Cassia tora L.). 1984. 41 f. Trabalho (Graduação em Agronomia) - Universidade Estadual Paulista, Jaboticabal, 1984.

BRASIL. Ministério da Agricultura e Reforma Agrária. Regras para análise de sementes. Brasília: Departamento Nacional de Produção Vegetal, DISEM, 1992. 365 p.

BUSS, A.; GLÓRIA, N. A.; JACINTHO, O. A. Viabilidade do uso de herbicidas em mistura com vinhaça para o controle de plantas daninhas em soqueiras de cana-deaçúcar. Planta Daninha, v. 1, n. 2, p. 49-56, 1978.
CARDOSO, V. J. M. Effects of temperature and seed coat on germination of Sida cordifolia L. (Malvaceae). Ci. Cult., v. 43, n. 4, p. 306-308, 1991.

CARDOSO, V. J. M. Germination studies on dispersal units of Sida rhombifolia L. R. Bras. Bot., v. 13, p. 83-88, 1990.

CHRISTOFFOLETI, P. J.; BACCHI, O. O. S. Efeito da aplicação de vinhaça sobre a população e controle químico de plantas daninhas na cultura da cana-de-açúcar (Saccharum spp). Planta Daninha, v. 8, n. 1/2, p. 60-70, 1985.

GLÓRIA, N.; ORLANDO FILHO, J. O. Aplicação da vinhaça: um resumo e discussão sobre o que foi pesquisado. Álcool Açúcar, v. 4, n. 14, p. 24-35, 1984.

KORNDORFER, G. H.; ANDERSON, D. L. Use and impact of sugar-alcohol residues vinasse and filter cake on sugarcane production in Brazil. Sugar Azucar, v. 92, n. 3, p. 26-35, 1997.

LABOURIAU, L. G. A germinação das sementes. Washington: Secretaria Geral da O.E.A., 1983. 173 p.

MAGUIRE, J. D. Speed of germination-aid in selection and evaluation for seedling emergence and vigor. Crop Sci., v. 2, n. 1, p. 176-177, 1962.

NAKAGAWA, J. Testes de vigor baseados na avaliação das plântulas. In: VIEIRA, R. D.; CARVALHO, N. M. (Eds). Testes de vigor em sementes. Jaboticabal: FUNEP, 1994. p. 49-85.

PÉREZ, E. R.; CARDOSO, D. R.; FRANCO, D. W. Análise dos álcoois, ésteres e compostos carbonílicos em amostras de óleo fúsel. Química Nova, v. 24, n. 1, p. 10$12,2001$.

SMITH, C. A.; SHAW, D. R.; NEWSON, L. J. Arrowleaf sida (Sida rhombifolia) and prickly sida (Sida spinosa): germination and emergence. Weed Res., v. 32, p. 103-109, 1992.

VAUCLAIR, C.; TARJUS, H.; SCHAETZEL, P. Permselective properties of PVA-PAA blended membrane used for dehydration of fusel oil by pervaporation. J. Membr. Sci., n. 125, p. 293-301, 1997.

VILLELA, F. A.; DONI FILHO, L.; SEQUEIRA, E. L. Tabela de potencial osmótico em função da concentração de polietilenoglicol 6000 e da temperatura. Pesq. Agrop. Bras., v. 26, n. 11/12, p. 1957-1968, 1991.

ZARPELON, F. Redução do volume de vinhoto. Stab: Açúcar, Álcool e Subp., v. 1, n. 2, p. 28-35, 1982.

Planta Daninha, Viçosa-MG, v.21, n.3, p.443-449, 2003 